USING ASSESSMENT DATA IN EDUCATION POLICY AND PRACTICE:

EXAMPLES FROM THE ASIA-PACIFIC

\title{
Citizen-led Assessments: A Model for Evidence-based Advocacy and Action to Improve Learning
}

Suman Bhattacharjea, Sehar Saeed, Rajib Timalsina, Syeed Ahamed

ISSUE 4, JUNE 2021 


\section{FROM THE EDITORS}

As we are completing this topical case study on citizen-led assessments (CLAs), countries around the world are enduring the second year of the COVID-19 pandemic. During 2020, schools were closed for a significant amount of time for more than 168 million children around the world. ${ }^{1}$ By March 2021, half of the world's student population (more than 800 million learners) was still affected by full or partial school closures. Schools in 29 countries were still completely shut. ${ }^{2}$ Even before the pandemic, education disruption was common for many students around the world. According to the UNESCO Institute for Statistics (UIS) data ${ }^{3}$, at the end of the school year in 2018, about 258 million children and youth were out of school. Almost half of these children were of primary and lower secondary school age (23\% and $24 \%$ respectively), and $53 \%$ of upper secondary age. Considering the far-reaching economic and social impacts of the pandemic that affect education systems, achieving Sustainable Development Goal 4 (SDG4) under the Education 2030 Agenda is at risk. More than ever, it is essential to understand where learners are at and how learning has progressed over the years before, during, and following the pandemic. Assessing and monitoring learning progress in education systems, including stagnation and loss, is crucial to investigate and understand the effects of the response strategies aimed at maintaining learning continuity; for example, distance and online learning. Continued monitoring once schools reopen will provide crucial information on how well learners and education systems are recovering from the disruption. Robust assessment and monitoring systems allow stakeholders to identify the most vulnerable and marginalized populations, who are often left out of school education and common school-based assessments. A key component of robust assessment and monitoring systems in many developing countries is CLAs.

Designed as household-based assessments, CLAs are implemented by local organizations who assess children in their homes, thus reaching the most marginalized children, families, and communities, often in remote areas. CLAs add an essential piece of information for truly monitoring progress and help realistically represent the learning levels of all children - at national, regional, and global levels. By using simple tools and easy-to-understand reports, CLAs engage parents and community members in discussions about learning and help foster understanding of the importance of ensuring quality education through civil action.

In this publication, members from organizations conducting CLAs in India, Pakistan, Nepal and Bangladesh provide an overview of the CLA model and illustrate a range of ways in which the model has been implemented in the four South Asian countries to monitor and improve learning.

\section{Ursula Schwantner}

Senior Research Fellow and GEM Centre Coordinator, ACER

\section{Mark Manns}

Associate Programme Specialist, Section for Inclusive Quality Education, UNESCO Bangkok

1 https://data.unicef.org/resources/one-year-of-covid-19-and-school-closures

2 https://en.unesco.org/news/one-year-covid-19-education-disruption-where-do-we-stand

3 http://uis.unesco.org/en/topic/out-school-children-and-youth 


\section{ACKNOWLEDGMENTS}

The following authors contributed to this topical case study:

Lead Author and ASER India: Suman Bhattacharjea, ASER Centre

ASER Pakistan: Sehar Saeed, Idara-e-Taleem-o-Aagahi (ITA)

ASER Nepal: Rajib Timalsina, Tribhuvan University \& ASER Nepal

ASER Bangladesh: Syeed Ahamed, Institute of Informatics and Development (IID)

The authors would like to thank the many people who supported the writing of this topical case study: Sheshadri Anandrao, Rukmini Banerji, Ranajit Bhattacharyya, Anoushka Gupta, Wilima Wadhwa (India); Samjhana Balami, Prabesh Raj Joshi, Sumit Kharel, Sakar Pudasaini, Prashamsha Simkhada, Pramila Bisunke (Nepal), and Gopal Dey (Bangladesh) 


\section{CONTENTS}

From the editors

Acknowledgments

Acronyms and initialisms

1. Introduction to citizen-led assessments

2. ASER India: Assessment to action:

A partnership to improve children's foundational reading and arithmetic

3. ASER Pakistan: Enabling citizen action to improve learning

4. ASER Nepal: A partnership model for local governments and youth to improve learning

5. ASER Bangladesh: A tool for education policy advocacy

6. Conclusion

7. References

8. Appendix: Additional resources about citizen-led assessments 


\section{ACRONYMS AND INITIALISMS}

$\begin{array}{ll}\text { ASER } & \text { Annual Status of Education Report } \\ \text { CLA } & \text { citizen-led assessment } \\ \text { CRP } & \text { Cluster Resource Person } \\ \text { CSOs } & \text { civil society organization } \\ \text { DSERT } & \text { Department of State Education Research and Training } \\ \text { EMIS } & \text { educational management and information systems } \\ \text { ICAN } & \text { International Common Assessment of Numeracy } \\ \text { IID } & \text { Institute of Informatics and Development } \\ \text { ITA } & \text { Idara-e-Taleem-o-Aagahi } \\ \text { LASI } & \text { Learning Assessment for Secondary Institutions } \\ \text { PAL Network } & \text { People's Action for Learning Network } \\ \text { SDG } & \text { Sustainable Development Goal } \\ \text { SEQAEP } & \text { Secondary Education Quality and Access Enhancement Project } \\ \text { SSA } & \text { Sarva Shiksha Abhiyan } \\ \text { TaRL } & \text { Teaching at the Right Level } \\ \text { UIS } & \text { UNESCO Institute for Statistics }\end{array}$




\section{INTRODUCTION TO CITIZEN-LED ASSESSMENTS}

\subsection{Background}

Across the world, large proportions of children are not acquiring foundational reading and numeracy skills, even after spending several years in school (UNESCO 2013, 2015). Despite its increasing visibility, this enormous global problem of 'learning poverty' (World Bank, 2019) has not received adequate attention in educational policy and practice. For example, foundational skills are rarely part of national, regional, or international large-scale assessments, which usually test students' understanding of content taught in their current grade or stage.

\subsubsection{What are citizen-led assessments?}

Against this backdrop, citizen-led assessments (CLAs) offer a model not only for generating evidence on children's foundational reading and numeracy, but also for connecting assessment results to remedial action on the ground. The CLA model is based on four main guiding principles:

- CLAs use oral assessments, conducted one-on-one with each child, since this is commonly accepted to be the most suitable method of assessing foundational reading and numeracy skills (UIS, 2016; Nag, 2017).

- CLAs are conducted in households in order to ensure inclusion of all children regardless of enrolment status, type of school, or school attendance on the day of the assessment.

- CLAs assess foundational reading and numeracy skills among school-aged children (typically 5 to 16 years old). The highest level assessed is the country's curriculum expectations for Grades 2 or 3, regardless of the child's age or grade.

- CLAs use tools that are quick and simple to administer and understand, which helps facilitate engagement of a wide cross-section of people, such as parents and community members as well as teachers and policy makers.

\subsubsection{How are citizen-led assessments used?}

Originally designed and implemented by Pratham Education Foundation in India in 2005, the relevance and adaptability of the CLA model is amply demonstrated by its organic spread across a diverse range of Global South contexts over the past 15 years (Figure 1). The core features of the model have been successfully adapted for use in a range of country contexts and for a variety of purposes, responding to individual country contexts and priorities. For example, in India, where the model originated, a large-scale survey each year of over half a million children generates representative estimates of children's foundational learning levels for different geographies, age groups, and grade levels. In Botswana, a similar assessment is conducted by school teachers in every school in to identify and track the progress of children in need of remedial intervention. In Uganda, the tool has been used in refugee camps to understand the learning needs of this highly vulnerable group of children. And in Mexico, in one of the states where the assessment was conducted, assessment results paved the way for the emergence of a range of initiatives by school and civil society actors to improve children's foundational skills.

In 2015, organizations in 14 countries across three continents came together to establish the People's Action for Learning (PAL) Network. These organizations use CLA tools to generate evidence on scale and/or to inform the design and evaluate the effectiveness of learning interventions. Beyond the work of these organizations, a 2019 review documented the use of CLA tools by 56 national and international organizations in 33 countries around the world. ${ }^{4}$ In 2019, the PAL Network developed the International Common Assessment of Numeracy (ICAN), enabling the first step in the generation of a common, comparable evidence base on children's foundational numeracy skills in Global South contexts. ${ }^{5}$ ICAN was implemented in one district in each of 13 PAL Network countries (PAL Network, 2020).

\subsection{How has the citizen-led assessment model been used in four South Asian countries?}

This topical case study describes some of the ways in which CLAs have been used in recent years in Bangladesh, India, Nepal, and Pakistan. In all four countries, the initiative is known as the Annual Status of Education Report, or ASER a word that means 'impact' in three of these four countries. ${ }^{6}$ ASER was first implemented in India in 2005; in Pakistan in 2008; in Bangladesh in 2014; and in Nepal in 2016.

4 These numbers are likely to be underestimations because all PAL Network tools are in the public domain and access does not need to be recorded.

5 See the Appendix for more information on ICAN.

6 This topical case study focuses on the use of the ASER tools as country-specific versions of the CLA model that have been implemented in South Asia over the past 15 years, prior to the recent development of ICAN. For more information about ASER, see the Appendix. 


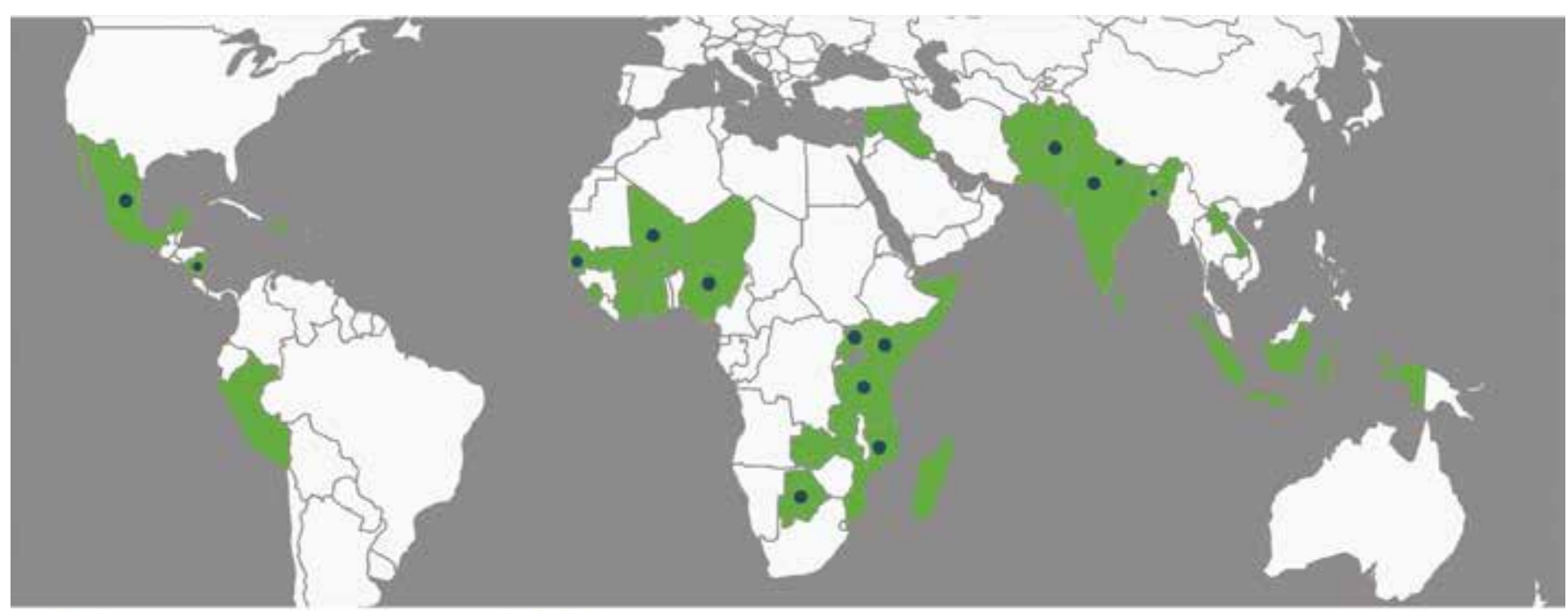

PAL Network Members

Education projects using citizen-led assessment tools or data

Figure 1. The CLA model in Global South contexts over the past 15 years

Several organizations in Afghanistan? have independently conducted CLAs based on the ASER model in different parts of the country, which may eventually add a fifth country to the South Asia hub of the PAL Network.

\subsubsection{The ASER initiative}

By design, ASER assesses foundational reading and numeracy skills. In all four countries, the tools follow the same assessment framework, adapted for their language(s) and curricular objectives. ${ }^{8}$ In each country, the reading test assesses knowledge of the symbol set, ability to decode simple and familiar words, and ability to decode words in connected text. Similarly, for numeracy, all four ASER assessments include tasks on number recognition (one-digit and two-digit), subtraction, and division. Within this common structure, actual items vary slightly across countries, based on curricular expectations in early primary grades. When developing

7 Over the past decade, ASER or ASER-like tools have been used by a number of organisations in Afghanistan, including Child Fund International in 2013; the Agence d'Aide à la Coopération Technique Et au Développement (ACTED) in 2013; Save the Children in 2015; and as part of the UNESCO Literacy Empowerment for Afghanistan Police (LEAP) program in 2016. In June 2018, a group aiming to seed a systematic initiative known as ASER Afghanistan piloted a survey in two districts of Kabul Province: Charasyaab and Paghman. Currently, a project aiming to establish a South Asian assessment alliance, led by Street Child and Pratham Education Foundation and supported by the Global Partnership for Education (GPE) and Oxfam IBIS, includes work in Afghanistan. The project envisages building the capacities of civil society organisations in participating countries to design, plan, collaborate, execute, analyse, report, and disseminate findings from citizen-led assessments.

8 For a discussion of validity of ASER assessment tools, see Vagh (2016). assessment items, compatibility with the national curriculum is ensured and difficulty levels are established based on extensive field trialing.

With regard to implementation in each of these countries, the ASER assessment has been used in a variety of ways in terms of scale, frequency, and objectives, often in collaboration with government and non-government actors. In each country, the assessment has been used to meet one or more of three distinct objectives:

- generating population estimates of learning based on large-scale implementation of the assessment with a sample of children

- measuring the outcomes of interventions aiming to improve foundational learning, by doing repeat assessments of a selected population of children over time

- advocacy around the importance of foundational learning, by using the tool, the process, and the data to communicate and discuss key issues with policy makers, community organizations, and parents.

In India and Pakistan, both countries with a long history of using CLAs, the ASER tool and process are routinely used in different ways to serve a variety of programmatic goals. Nepal and Bangladesh, more recent adopters of CLAs, have a less extensive trajectory with respect to the model's use. 


\subsection{Outline of this report}

The country case studies that follow provide a brief overview of each country's ASER initiative, followed by an in-depth description of one specific example of how the tool, process and/or data have been used. Taken together, these four country case studies illustrate the range of ways in which ASER has been used in South Asia:

- In the case of ASER India, we examine how ASER is used as a tool for teachers, summarizing a 5-year collaboration with the state government of Karnataka to identify and provide remedial instruction to children in need of support for building foundational reading and numeracy.

- For ASER Pakistan, we focus on how the model works as an advocacy tool, especially to engage stakeholders from the villages in understanding, discussing, and finding solutions to the issue of poor foundational learning.

- The case of ASER Nepal describes how ASER became a useful strategy for a newly elected local government, which under the 2015 constitution had acquired a range of new powers and responsibilities, but insufficient resources to support planning.

- The case of ASER Bangladesh describes the ways in which CLAs offer important inputs for policy advocacy efforts around the issue of meeting national and international learning goals.

In the conclusion, we reflect on the use of the CLA model in light of the ongoing COVID-19 pandemic. The Appendix provides ASER-related resources that can be consulted for more information on the CLA model generally, as well as on the individual country initiatives. 


\section{ASER INDIA: ASSESSMENT TO ACTION: A PARTNERSHIP TO IMPROVE CHILDREN'S FOUNDATIONAL READING AND ARITHMETIC}

\subsection{Background}

ASER is a rural household survey that generates estimates of foundational reading and arithmetic abilities among children aged 5-16 in rural India. Facilitated since 2005 by the nongovernment organization Pratham Education Foundation, it is conducted with the support of partner institutions across the country, reaching more than half a million children each year.

Although today ASER is widely recognized as a source of representative data on children's foundational learning in India, it was not originally conceived of as a model for largescale learning assessments. Rather, the simple assessment tool (Figure 2) was originally designed to help Pratham teams adopt a uniform approach to understanding and discussing what children could and could not do, and use appropriate teaching and learning activities to help them progress, thus connecting assessment and teaching. It was designed to be simple, in order to facilitate communication across the large Pratham network as well as with parents and communities about children's learning. Aggregated across children, the assessment could generate estimates of what children could do in selected populations or geographies, whether in individual village 'report cards' to be discussed with community leaders, or in a nationwide ASER report; equally importantly, at the individual level (whether learner, parent, or teacher), the tool offered a simple and effective means of communicating with those who were not assessment experts, both within and outside the education system.

As originally designed, therefore, the objective of the ASER assessment tool was not to generate data on scale, but rather to make the problem of poor foundational learning visible, in order to support remedial interventions aiming to help children build these foundational skills. This approach, known in its current iteration as Teaching at the Right Level (TaRL), has been rigorously evaluated on multiple occasions and shown to be effective at improving children's foundational skills in a short period of time. ${ }^{9}$ Because the model is simple, frugal, and scalable, it has been implemented by many governments and communities across the globe. This case study describes one such experience: its adoption in 2016 and subsequent scale-up by the government of Karnataka, a state in the south of India.

9 See the Appendix for more information on TaRL and links to evaluation reports.

\section{READING TOOL (SAMPLE 1)}

Story

(Std II level text)

A big tree stood in a garden. It was alone and lonely. One day a bird came and sat on it. The bird held a seed in its beak. It dropped the seed near the tree. A small plant grew there. Soon there were many more trees. The big tree was happy.

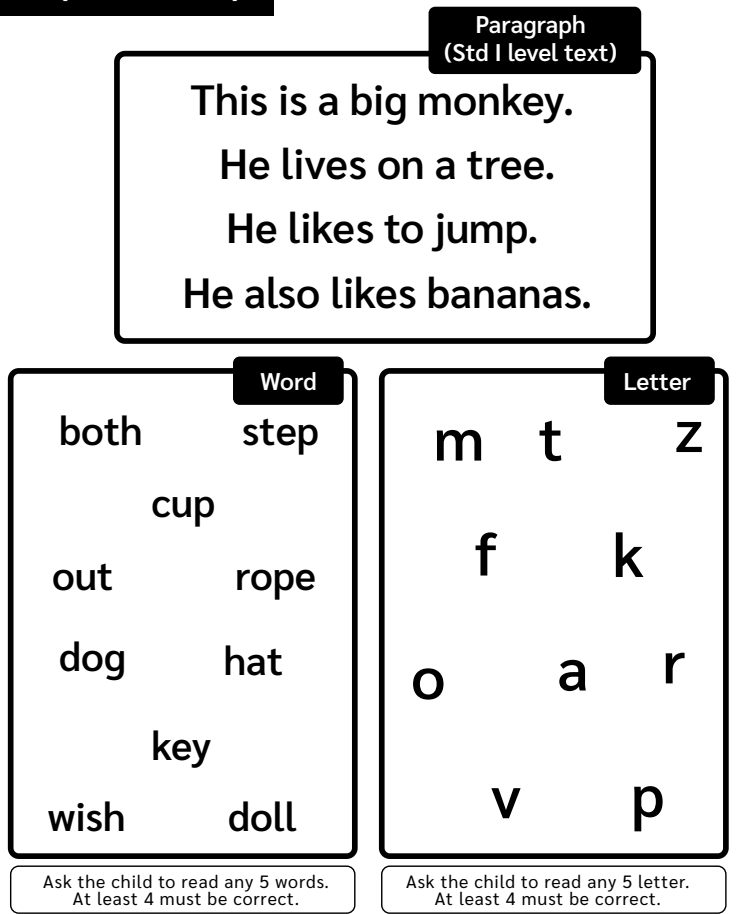




\subsection{Context}

In 2016-17, the state of Karnataka had about 57,000 primary schools, in which over five million children were enrolled across Grades 1-5 (NIEPA, 2018). The annual ASER survey, which had been routinely conducted in rural Karnataka as elsewhere in the country for over 10 years, showed that while enrollment levels in the state were very high ${ }^{10}$, a very large proportion of children in the final year of primary school were unable to read fluently. In 2016, for example, $42 \%$ of Grade 5 children could not read Grade 2 level text in Kannada, the official medium of instruction in the state (ASER Centre, 2017).

Although similar results had been seen in Karnataka every year since ASER was first implemented in 2005, there had been limited acknowledgment of the issue by government actors. As was the case elsewhere in the country, official emphasis in both teaching and assessment had focused on grade-level content. Children's lack of foundational skills was an 'invisible' problem: a child who turned in a blank test paper was simply assumed not to understand the content being tested, and the fact that she could not read the questions on the test often went unnoticed.

\subsection{Early implementation}

This situation began to change in Karnataka in 2016 when Ajay Seth, then Principal Secretary to the government of Karnataka, attended an event in the national capital at which Pratham CEO Rukmini Banerji had been invited to speak. In her presentation, Dr Banerji described both the problem of poor foundational learning and its solution in the form of the TaRL model. Interested, Mr Seth subsequently reached out to other key members of the state education hierarchy, including the Director of the Department of State Education Research and Training (DSERT) and the State Project Director of Sarva Shiksha Abhiyan (SSA), to learn more. The model seemed to be worth testing, and later that same year, DSERT decided to pilot a remedial intervention - Odu [Read] Karnataka - in three of the state's 30 districts, aiming to improve foundational reading and arithmetic skills of children in Grades 4 and 5 .

Central to the pilot intervention and its subsequent scale-up was the fact that the intervention was implemented by staff already within the education system, with Pratham providing materials and training. A key element was the selection and training of a group of 500 Cluster Resource Persons (CRPs) ${ }^{11}$

10 Enrollment among the 6-14 age group has been above $95 \%$ in Karnataka for well over a decade.

11 Cluster Resource Persons are staff at Cluster Resource Centres, established in each block of the country to provide decentralised academic supervision and support to teachers.

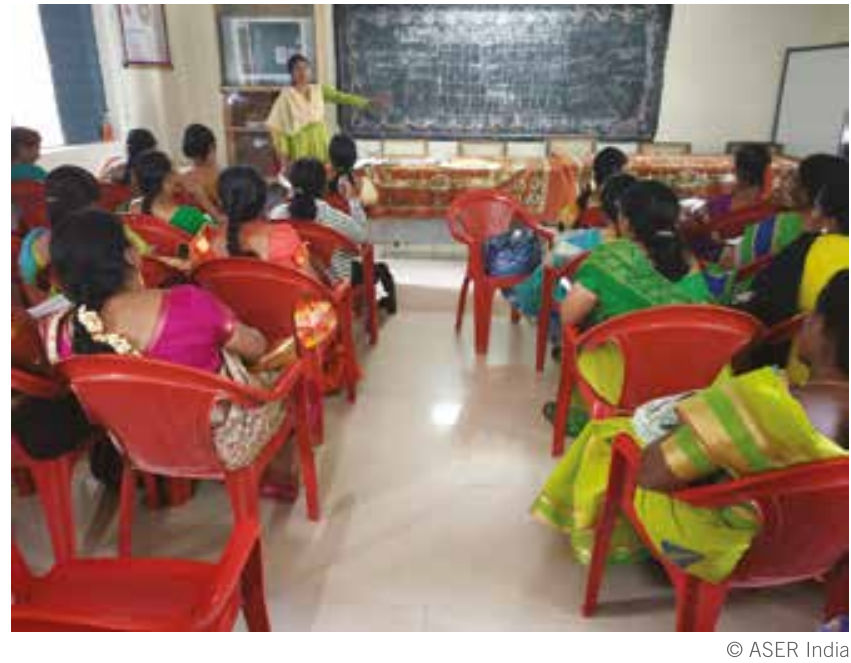

who were tasked with providing direct support and supervision to the more than 4000 schools and close to 75,000 children covered by the pilot intervention. As part of their training, the CRPs were required to implement all intervention activities themselves for 15 days, working in classrooms to conduct the assessment, group the children based on the type of support needed, and use methods and materials appropriate for each group to provide remedial instruction for two hours a day. This key step enabled the CRPs to acquire a thorough understanding of the model and therefore be more effective as trainers and supervisors. It also created a group of actors within the system who understood the need for this kind of intervention, appreciated what it could do, and could defend it in the face of resistance from those who were opposed to its implementation.

\subsection{Scale up}

In the pilot intervention during 2016-17, targeted children showed impressive learning gains; for example, the proportion of children in Grades 4 and 5 who were able to read at Grade 2 level almost doubled, from 40\% during the baseline assessment to $75 \%$ just a few months later. However, those closely involved with the program pointed out that it was not so much these remarkable results that generated the buy-in to secure the program's sustainability within the system, but rather the assessment process itself that made the problem of poor foundational learning visible.

In school systems that are habituated to teaching and evaluating grade-level content, it is easy to assume that after a few years in school, children are able to read and do basic arithmetic - despite 15 years of ASER reports that provide ample evidence to the contrary. The turning point often comes when individual teachers are given the opportunity and the tools to be able to see the problem for themselves. The five-minute ASER assessment enables a teacher (or a parent 
or supervisor) to realize that 10-year-old Sheela, or eightyear-old Aakash, or 14-year-old Madhavi - all children who have been enrolled in school for several years - are unable to read a passage that is clearly shorter and simpler than most of the content of their grade-level textbooks. In Karnataka, as elsewhere, it was this process of teachers being able to generate their own evidence and understand the situation for themselves that was critical to creating buy-in.

Convinced that this model could indeed deliver positive results, DSERT, SSA, and the Karnataka Department of Public Instruction continued to scale the program over the next two years in collaboration with Pratham. The team of CRPs trained teachers to conduct the assessment, group children, set learning goals, use level-appropriate methods and materials, and track students' progress, while Pratham continued to provide overall support. In 2017-18, 10 new districts were added to the existing three pilot districts. Five additional districts were added in the academic year 2018-19, reaching close to 11,000 schools and more than 240,000 children in all. The program continued until 2020, when the COVID-19 pandemic caused schools to close down.

Results from 2018-19, the last full year of implementation, show that children's acquisition of foundational reading and arithmetic improved enormously. In just one year, the proportion of participating children able to read at Grade 2 level almost doubled, from one-third to almost two-thirds of participating children (see Figure 3); and the proportion who could solve a three-digit by one-digit division problem increased from under $40 \%$ to just over $70 \%$ in the same period.

\subsection{Conclusion}

The rapid improvements visible in children's foundational reading and arithmetic abilities in Karnataka are not uncommon in locations that have used the TaRL approach, which incorporates the ASER assessment as an integral part of the teaching and learning cycle. While key aspects of the approach have been extensively described elsewhere ${ }^{12}$, four elements of the Karnataka experience, also common to other locations where TaRL has been used successfully on scale, are worth pointing out.

1. The ASER tool was effective as a mechanism for rapid generation of data about children's learning levels, and also as a process that very quickly made the "invisible problem" of poor foundational skills visible, immediate, and real. The assessment became about helping children learn, rather than simply collecting data.

2. Program implementation by a core team of CRPs from within the existing system was key to creating capacity, sustainability, and appetite for change within the system. Careful selection, training, and nurturing of this group was critical to the state's ability to scale up the program, including the selection of a team of Master Resource Persons who travel throughout the state to support the program wherever needed.

3. The program had support from the very beginning from key senior officials in different institutions within the state education apparatus. Its sustainability was thus not subject to the permanence of any single officer within this group, which also led to vertical and horizontal collaboration, and coordination within and across different

12 See Teaching at the Right Level in the Appendix

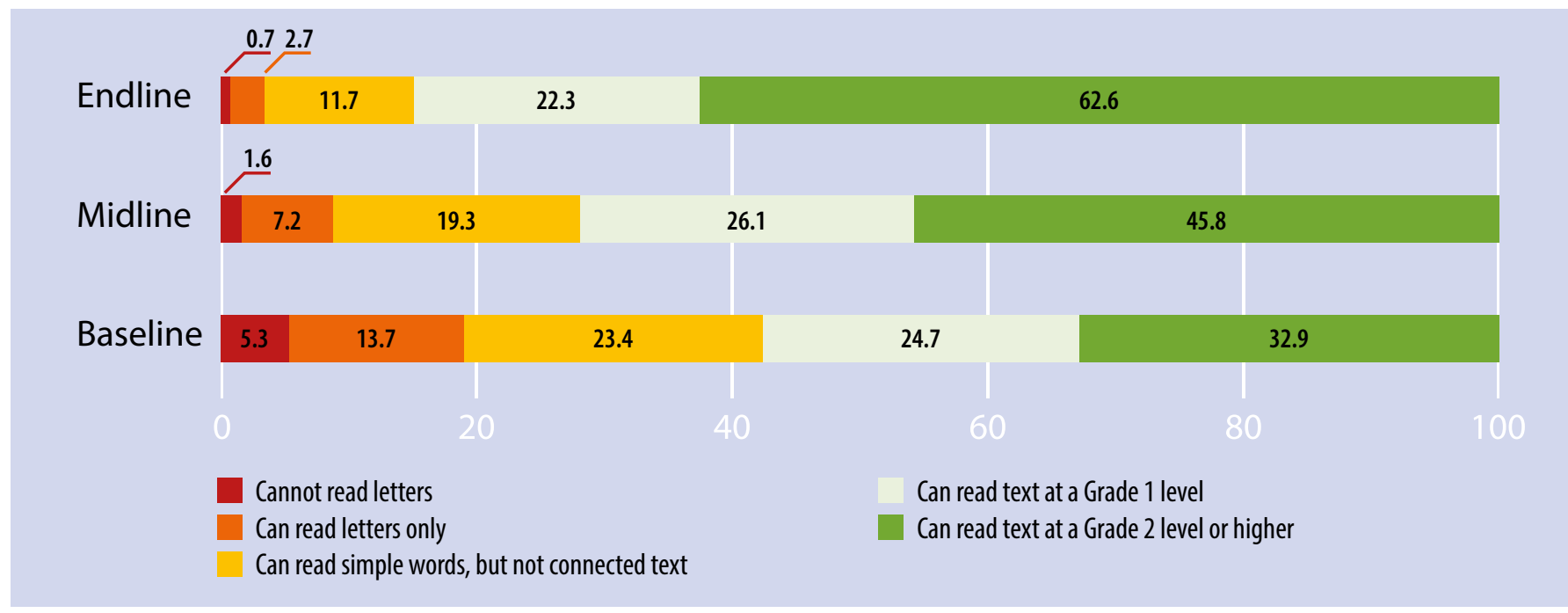

Figure 3. Odu Karnataka: Improvements in reading outcomes from baseline to midline, 2018-19 
institutions and levels of the system. Support from senior officials has often continued well beyond their tenure as officers in the education bureaucracy, and has been a key element contributing to the program's sustainability over the past five years.

4. The ASER tool was central in enabling regular monitoring of program impact via the analysis of aggregate data, which in turn facilitated directing resources to where they were most needed. For example, monitoring visits could be scheduled more frequently to schools where data showed that children were making less progress than expected. In resource-constrained environments, this ability to quickly assess progress and target resources as needed is an important element in ensuring that teachers and schools, as well as children, obtain the support they need.

Over the years, the TaRL model has been used by volunteers in communities, by teachers in schools, and by Pratham teams themselves in thousands of locations across India to assess children's needs and help them acquire these foundational skills. In the wake of the COVID-19 pandemic, when school dropouts and "learning loss" are expected to increase, especially among the most vulnerable populations, the ASER assessment offers a rapid mechanism for identifying children who lack basic reading and arithmetic abilities. Whether used in conjunction with the specifics of the TaRL methods and materials or other kinds of remedial support, the ASER assessment tool offers simple, effective ways to help focus attention on the importance of building firm foundations. 


\section{ASER PAKISTAN: ENABLING CITIZEN ACTION TO IMPROVE LEARNING}

\subsection{Introduction}

ASER Pakistan is Idara-e-Taleem-o-Aagahi (ITA)'s flagship program. ITA is a civil society, citizen-led learning accountability initiative that has influenced the discourse and action on "learning" at provincial, national, and global levels. ASER is a unique data-driven policy, systems, and sector planning tool that identifies learning challenges. The rapid, child-friendly ASER Pakistan assessment tool was conceived and tested in 2010. Since then, ASER Pakistan tools have been implemented at scale, in all rural districts across Pakistan and selected urban districts, allowing the comparison of learning outcomes and access between urban and rural areas. The ASER survey generates estimates of schooling and basic learning status of children in the age group 5-16 through household-based assessment. In every sampled village, ASER surveys collect information from one government and one private school regarding teacher qualification, facilities, budgets given to schools etc.

The survey is implemented in political constituencies to urge politicians to take action for education. All three learning tools (Urdu/Sindhi; English and Arithmetic) have been converted into Pakistan Sign Language (PSL) and Braille formats for hearingand vision-impaired children. The tools have also been used orally, and on mobile apps and cell phones, increasing reach and robustness of the implementation. As such, ASER Pakistan has the capability of being used widely, including during the current COVID-19 pandemic and its recovery pathways. The evidence generated by ASER becomes a basis to improve learning outcomes.

ASER launched its first report on the quality of learning in Pakistan in 2010. Since then, efforts have intensified to improve the capacity of educated citizens across Pakistan, to collect data on learning across all provinces, and to disseminate it to the public through diverse traditional and new media. ASER Pakistan's communications strategy involves government counterparts, citizens, teachers, parents, and village elders. This has played a vital role in empowering communities to contribute to shaping education systems. Thematic ASER report cards that examine learning outcomes across gender, disability, and political constituencies have generated discourse for evidence-based advocacy at national and provincial levels. Today, ASER Pakistan is symbolic of the power of citizens coming together in an organized manner with systematic capacity building for measuring children's learning capabilities.

\subsection{A citizen-led accountability movement to improve learning}

ASER believes that building a solid evidence base on learning outcomes is necessary in order to understand children's learning levels and to identify challenges of the education system. By communicating this evidence to a wide range of stakeholders, including primary actors and the public, informed understanding and debate about children's learning can be fostered, and change can be initiated to improve learning. Through a process of involving citizens in conducting the ASER survey, disseminating the findings in village gatherings, and community decision-making, ASER translates national education issues into a citizen-led accountability movement at the local level. From the bottom up, ASER mobilizes citizens to conduct the survey and organize village gatherings. The ASER findings are also communicated at the district and provincial level, through to the national level, to engage a broad audience of policy makers, civil servants, academics, and the general public.

The following sections describe ASER Pakistan's accountability movement to improve learning.

\subsubsection{Mobilizing citizens at the local level}

ASER mobilizes ordinary citizens/volunteers to conduct the survey on an annual basis. The ASER survey data collection process begins with two volunteers visiting a randomly selected target village. They make their way to the central space in the village and share their purpose with village leaders and community members. A rough map with coordinates is collectively drawn up, and the village is divided into quadrants for selecting households for participation. The first house is selected randomly and thereafter every fifth household; five households per quadrant are included. In each of the 20 chosen households, the survey team knocks on the front door or gently lifts the heavy cloth to seek permission and to explain the purpose of the visit. Children, mothers, and grandmothers

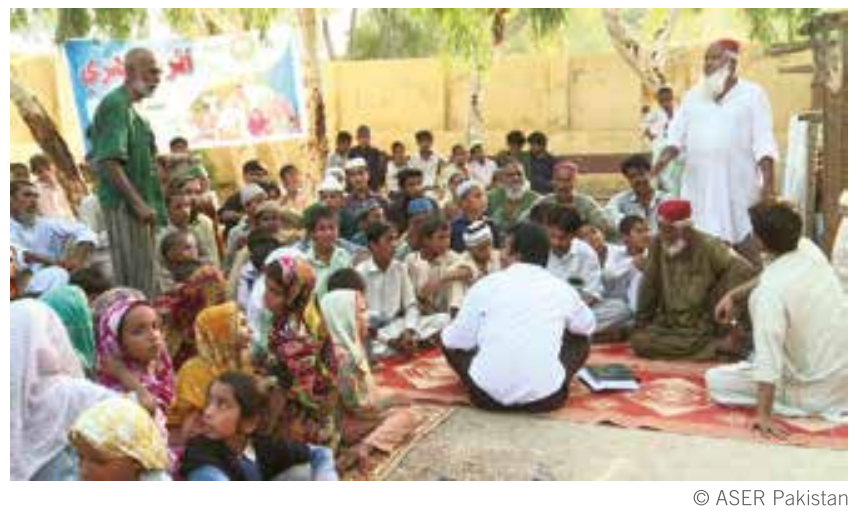


often gather to ask what will this survey do for them: no one has come to assess their children's learning before, so will it lead to something good for their children? The team settles in to fill out the household survey form and then conduct the children's learning assessment for all 5-16 year olds present in the household. Usually, a kind family member insists that the volunteers enjoy a glass of fresh milk or sharbat (juice) as a thank you for their dedicated service.

Each year ASER holds village gatherings, called Katcheries, Baithaks or Jirgas depending on the area of Pakistan. ${ }^{13}$ The gatherings are organized at school and/or community sites and bring together community members, youth, teachers, parents - both mothers and fathers - and government field officers. ASER team members share the ASER findings, mobilize volunteers for improving the status of education, and motivate parents to send their children to school. The gatherings are also a chance to decide on actions to be taken by all the community members to improve education in the village.

The village gatherings begin with ASER team members sharing the objectives of the conversation and reminding the attendees of the survey recently conducted in the village. The results are then shared, emphasizing that while the survey is based on a sample of 20 households, the trends represent the whole village. This information then leads to many conversations and reflections in the community, acknowledging gaps in taking action for education, lapses in accountability, and the role of the village school, its teachers, and the larger system of education. The discussions are like a mirror for the community and parents: they begin to see more clearly the state of learning of their own children and education in public and private schools in their community.

Once the discussion reaches a climax, the ASER facilitators give a call to action.

- Who will ensure that children are enrolled on time and brought to the school?

- Who will take turns to see if the teachers come to school on time?

- Who is educated at least up to Class [Grade] 12 and will volunteer to teach an eight- to 10-week accelerated literacy and numeracy program for out-of-school children and at-risk in-school children with the lowest learning levels?

- Who will write to the government with a request to improve the facilities and shortage of teachers?
The community is stirred into action, and the energy for education is unleashed. By engaging citizens to act as monitors and decision-makers for the public and private provision of education, ASER is a testament to how school systems and education policy can be influenced at the grassroots level. It is due to this engagement that government and private citizens alike eagerly await the results each year.

\subsubsection{The broader communications strategy}

At its core, ASER is people-driven, both in the survey design and communication of its results. The message is simple: parents, citizens, and governments must recognize the learning crisis in their homes, communities, villages, districts, and provinces, and take urgent action to improve the quality of education.

To create awareness among the different stakeholders of the learning levels of children, both in and out of school, the ASER findings are disseminated widely at various levels (see Figure 4). Communications materials include the main ASER report, as well as easy-to-understand content such as posters, district report cards, ranking sheets by indicators (including access, learning levels, and enrollment in government versus private schools), and policy briefs. The findings are also communicated using different media, such as newspapers, TV campaigns, and social media.

ASER's primary audiences are the communities and parents who can be empowered to stimulate national debate and bottom-up action. The community gatherings described earlier are therefore a core element of the ASER communication strategy. The launch of the ASER findings at the district seminar stimulates engagement at the district level. The ASER findings are also launched at the provincial/state level, and supported by policy seminars and dialogues on key thematic areas presented by the ASER findings. Beyond that, the national launch of ASER findings targets academics and researchers, civil servants, parliamentarians, and policy makers, as well as the general public.

\subsection{Conclusion}

ASER Pakistan efforts are nationwide, and engagement with all kinds of stakeholders including communities, youth, teachers, policy makers, and media has led to a realization among the general public and policy makers that simply putting children in schools is not enough to generate learning gains. There must be greater concern about why children are not currently learning and how learning can be improved.

\footnotetext{
13 In Punjab and Balochistan, these meetings are called Baithaks; in Khyber Pakhtunkhwa and FATA they are called Jirgas; and in Sindh they are known as Katcheries.
} 


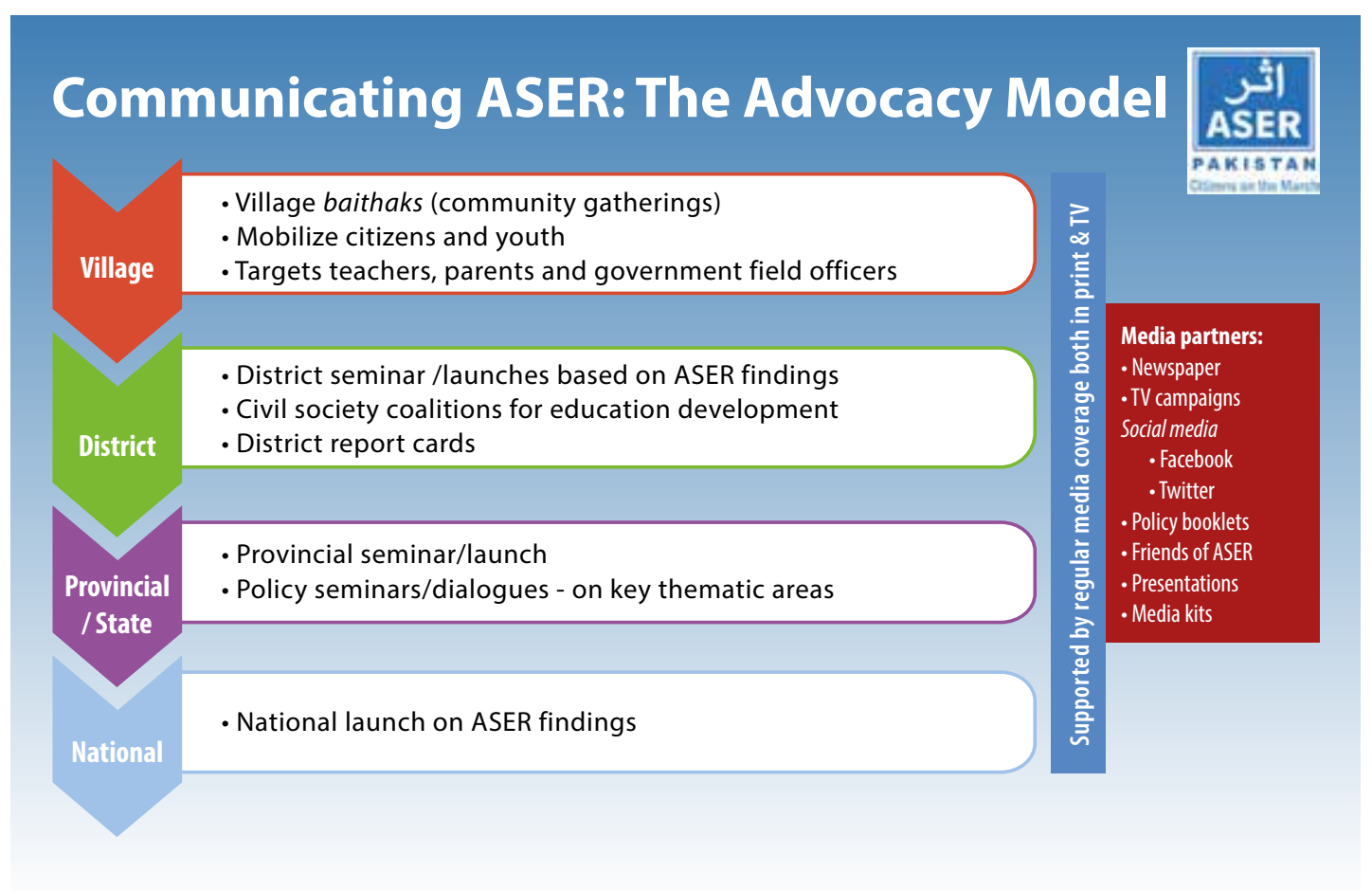

Figure 4. ASER Pakistan's communications strategy

As a result, the citizen-led accountability movement of ASER has had an impact on learning improvement programs, education research, and training programs, as well as government documentation. For example:

- ASER has informed the design and implementation of major learning improvement programs at ITA with its assessment tools embedded in these activities:

Chalo Parho Barho (CPB)/Accelerated Learning Program. This program imbibes the principles of TaRL interventions (2012-20) like Pratham's Odu Karnataka program (see section 2). Implemented in schools, it targets in-school children at risk in Grades 3 to 5, and out-of-school children, aged six to 13 years. In Pakistan, it has been tested in Punjab, Sindh, KP, and Balochistan.

The Siyani Sahelian "wise friends" program (2018-21) targets highly vulnerable adolescent girls aged from nine to 19 years who have either never enrolled or have dropped out of school. All girls are provided a learning boost through an accelerated learning program of 30-60 days, or as needed, based on the TaRL approach. ASER tools are used throughout the program, providing evidence on learning outcomes at the baseline, midline and endline. Thus the TaRL approach is the first stepping stone for all learners (36,000 to date) prior to their transition to upper primary, middle and secondary academic learning pathways supported by life skills (http://itacec.org/ SiyaniSahelian/).

- The data from ASER reports are widely used for postgraduate/PhD research, in university coursework (for Masters in Education) in Pakistan, and at several universities abroad, including the Teachers College at Columbia University, Durham University, Cambridge University, LUMS-SOE, and IBA University.

- ASER is referenced in key government documents such as the Economic Survey of Pakistan by the Ministry of Finance each year in the chapter on education (Ministry of Finance, 2012-13).

ASER tools support and influence many diverse learning assessments conducted for impact evaluations at the School Education Department, Punjab (Learning \& Numeracy Drive); the Citizens Foundation schools; in prisons; low-cost private schools, etc. In short, ASER is a public good and service. It has touched the lives of millions of people, youth, civil society organizations (CSOs), and governments, who use it for diagnostic surveys, and as benchmark data on children's foundational learning in education sector plans. Building on the impact and success to date, ASER Pakistan will continue to support the general public by providing evidence that can be used to improve learning of all children. 


\section{ASER NEPAL: A PARTNERSHIP MODEL FOR LOCAL GOVERNMENTS AND YOUTH TO IMPROVE LEARNING}

\subsection{Background}

Using the example of the 2017 municipal level ASER in Budanilkantha, this case study demonstrates how ASER became a useful strategy to mobilize and upskill citizens, especially youth, to collect data on children's foundational learning levels, and to support local governments to use this evidence for improving education.

ASER Nepal is led by GalliGalli, a non-profit organization. The initiative began in 2016 with a pilot assessment of children's foundational learning levels in English, Nepali, and numeracy. This pilot was undertaken in one district in southern Nepal in collaboration with Tribhuvan University and Kathmandu University, and mobilized 68 citizen assessors to reach 600 households. Based on the successful pilot, the assessment in Budanilkantha, a suburban/exurban area on the outskirts of the capital, Kathmandu, was implemented with funding by the local government. In 2019, ASER Nepal was scaled up to cover a whole province, Province Two, reaching 45,500 households and deploying 5608 citizen assessors.

Between 1996 and 2010, Nepal went through a period of tremendous social and political upheaval. In this period, a Maoist insurgency grew to a nationwide conflict, a coup deposed a democratically elected government, an ancient monarchy was removed, and a republic was declared; all the while, strikes, street protests, and political violence were commonplace. After a peace treaty with the Maoist rebels was signed in 2006, Nepal went through another 10 years of a contested constitution-making process with a series of short-lived governments. In 2015, a new constitution was finally promulgated and shortly afterwards, local governments were elected for the first time in 20 years. Under the new constitutional provision, Nepal restructured its administrative units into seven provinces and 753 local governments. The local governments comprise both the rural and urban municipalities and are the key authority in school education. The new constitution has given the authority to regulate education up to Grade 12 to the 753 newly created and elected local government units, and the roles of province and federal government have been limited to monitoring.

However, these local governments have faced challenges. While they have constitutional authority over education, the acts and directives that actually permit them to exercise power are limited. The adjustment of civil servants from the previously centralized system to deployment in the subnational level has been incomplete, thus they are short-staffed. Oftentimes, they do not have access to critical data such as the educational management and information systems (EMIS).

In this context, the question of how to empower and assist these newly created local governments has occupied many, including the ASER Nepal team at GalliGalli.

\subsection{The ASER Nepal partnership model}

The ASER Nepal partnership model is based on a bottom-up approach. This approach engages socially active local youth in urban educational hubs to work with local governments to assess children's foundational learning levels, advocate for education, and use the findings to make improvements in education. As such, the ASER Nepal partnership model serves two major purposes:

- mobilizing and upskilling local youth through the training to conduct the assessment in the municipality

- gaining data on children's foundational learning levels in English, Nepali, and numeracy for education planning and improvement.

The responsibilities in this partnership model are shared between the local government, the youth assessors, and the ASER team. The local government provides the funding for the assessment, and helps recruit local youth who implement the assessments in the municipality. The ASER team designs the assessment and survey tools, trains the young assessors, manages and analyses the data, and prepares the report on the assessment findings. The findings are then shared and discussed with the local government to be used for education planning and improvement.

The ASER Nepal partnership in the Budanilkantha Municipality was initiated in 2017. The newly elected mayor, Uddav Kharel, had learned about the ASER Nepal pilot in 2016 from a young member of his secretariat staff. This staff member had been a volunteer teacher at a rural school where ASER Nepal training had been conducted. Inspired by the young staff member's experience, the mayor decided to visit the ASER Nepal team at GalliGalli to learn more about the assessment and how it is implemented in the households. Soon after the mayor's visit, the Municipality and GalliGalli agreed to work together to conduct ASER in Budanilkantha.

\subsection{Mobilizing and training youth assessors}

To implement the ASER Nepal partnership model in Budanilkantha, the municipality identified 200 volunteers between the age of 18 and 26 who were interested in social work. The ASER Nepal team recruited and trained the 200 youths over a period of five days in implementing 
the assessment. As part of this training, the local youth were upskilled - they could undertake the household sampling in the municipality, implement the learning assessment in the households, and carry out basic reporting skills. They were instructed how to compile the assessment data in a table, interpret the findings, and give feedback to the parents. At the end of the training, 156 youth were selected as assessors, based on a practice and written test about the assessment process.

The selected assessors visited a random sample of 300 households in each ward. In each selected household, all children aged 5-16 were assessed one by one in English, Nepali, and numeracy. The assessors also collected important background information at the household level, such as the child's schooling status, family wealth, and parental education. With the household survey, the assessors also collected information about the birth registration of all children in the household aged $0-3$ years, pre-primary enrollment status of all children aged 4-5 years, and if household members of $16+$ years are accessing social services.

The assessors visited all schools of the municipality to gather information about infrastructure available in the schools, such as classrooms, toilets, computers, and educational materials; management issues like existence of a school management committee, school improvement plan, and teachers' appointments with students; enrollment and actual attendance of students; water, sanitation, and hygiene facilities; and internet, electricity, and other facilities necessary for a modern education. Implementing the assessment in their neighborhoods enabled the young assessors to engage with the participating families about the importance of foundational skills and learning.

To monitor the Budanilkantha ASER, a number of socially active youth from local universities from all around Nepal were also recruited. The monitors were trained over the course of a month, a few weeks before ASER began. The monitors ensured the households were selected as indicated in the sampling frame. They also checked and verified that the learning assessment was implemented following the ASER Nepal guidelines and that the data was recorded appropriately in the data collection forms.

\subsection{Using the ASER findings}

The findings of the Budanilkantha ASER on children's learning levels in English, Nepali, and numeracy, and the resulting policy recommendations, were presented to the mayor's office in the ASER Budanilkantha report (ASER Nepal, 2018). The mayor's office also invited the ASER Nepal team

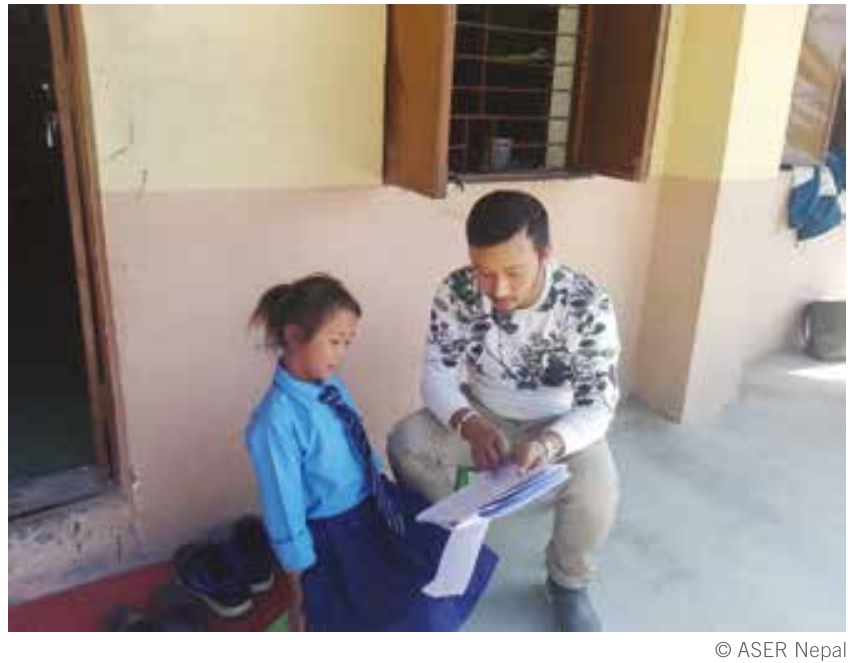

to convey the major findings at a meeting of the executive council of the municipality, the highest policy-making body at the local government. Following this meeting, the education subcommittee of the executive council called for a municipalitylevel meeting of headmasters to discuss implications of the ASER findings. In response, the municipality considered the policy recommendations from the ASER report in the budget planning process for the fiscal year 2019-20, and several new policies were adopted that were directly linked to the ASER findings.

The major findings of the ASER Budanilkantha report, resulting policy recommendations, and examples for respective policy response are summarized below.

Overall, the assessed learning levels of children aged 8-16 in English, Nepali, and numeracy were low in Budanilkantha. About $40 \%$ of them could not read the Nepali story with fluency, about $25 \%$ could not read the paragraph in English, and about 30\% could not perform a Grade 2 level division problem. Students attending government schools in Budanilkantha performed significantly lower than on average in English literacy. However, low learning levels were observed in students attending both government and private schools. The ASER report therefore recommended all types of schools (government, trust, and private schools) be considered in the efforts to systematically improve learning outcomes (ASER Nepal, 2018). Possible measures were discussed with stakeholders in several meetings of the municipality's education wing.

As for the age group of 12-24 year olds surveyed in the household survey, only about $1 \%$ responded that they have had access to formal vocational or skill development training in the municipality. The ASER report therefore recommended the improvement of access to relevant vocational and skill 
development programs for the local community (ASER Nepal, 2018). The municipality has since taken steps towards establishing a specialized vocational school.

Another important indicator collected with the household survey was children's school enrollment: $99 \%$ of schoolage children (including preschool) in the Budanilkantha Municipality reported as enrolled in either preschool or school. An analysis of background characteristics collected with the ASER survey did not reveal any discernible pattern in out-ofschool children that could inform specific measures to help encourage the remaining 1\% to attend school (ASER Nepal, 2018). It was therefore recommended that measures be taken at the ward level; for example, as part of the annual school admission campaign of the Nepal Government. Ward chairs and members are state representatives and have the detailed local knowledge that may be required to help bring out-ofschool children back to school. For example, ward members may be able to identify children who are otherwise hard to reach, such as children from temporary shelters, or children from seasonal migrant families who come to Budanilkantha from rural areas of Nepal in search of work. As a response, in the campaign year 2019, the local leaders and school stakeholders of Budanilkantha visited all the neighborhoods of the municipality to ensure that all children were enrolled in schools.

In addition to enrollment, student attendance is another important indicator to ensure learning. During the time of data collection, only $74 \%$ of students were observed in attendance in government schools, as compared to $92 \%$ in schools overall (ASER Nepal, 2018). It was therefore recommended that school management practices in government schools include effective measures to ensure school attendance. Such measures could include, for example, regular meetings with parents, and home visits to encourage attendance.

In terms of school infrastructure, government schools reached average levels on many measures such as the use of chalkboards, electric resources in classrooms, and libraries. On some infrastructural measures, such as having usable toilets, sufficient classrooms, and access to filtered drinking water, government schools performed better than the average. This reflects an investment by both the state and civil society in school infrastructure over the past decade. Yet, government schools underperformed on the management and upkeep of this infrastructure. For example, while government schools had more early-grade-friendly hand-washing points $(95 \%$ in government schools versus $83 \%$ in all schools with earlygrade students), they also reported more hand-washing points without soap (53\% in government versus $37 \%$ in all schools with early-grade students) (ASER Nepal, 2018). It was therefore recommended that in addition to infrastructure investment, a focus should be on improved management of school infrastructure and greater accountability to keep infrastructure well maintained. As a response, these issues were extensively discussed in the regular monthly meetings of head teachers at the municipality level.

\subsection{Conclusion}

The motivation to implement the ASER Nepal partnership model is multifaceted. This was noted by the ASER team in conversations with the mayor of Budanilkantha and other local leaders. The mayor, for example, saw the ASER model primarily as a way to fulfil a campaign pledge he had made to provide local youth with real-world skills that would increase their employability. The approach of assessing children in the home also provided an opportunity for the mayor to reach and demonstrate to voters that his government was taking action to improve education.

Another important factor for the municipality was the local relevance of the ASER approach. As an experienced local leader said, "Many people from outside come and do surveys but we don't know why it matters in our locality. I will support you, because our own young people must learn this skill of learning assessment. Maybe it will put something in their pockets in the future." This statement demonstrates the success of the ASER Nepal partnership model against the two goals of mobilizing and upskilling local youth, and collecting data on local children's learning levels in their homes in order to engage with and improve education in the municipality.

The introduction of new education policies at the local government level, based on the ASER findings, show further proof of the success of the ASER partnership model.

Highlighting the politically expedient opportunities of the partnership model, including local relevance and ownership - that is, mobilizing and upskilling local youth to implement the assessment under the patronage of the local government; generating large-scale awareness for issues of education in the community; gathering evidence on local children's learning levels to develop strategies, policies, and processes to improve learning - has been important to gain buy-in for undertaking ASER in Budanilkantha.

As a result, the idea of leveraging citizen volunteers to work on local issues was later internalized by the municipality. A few months after the ASER implementation, the municipality started Yuwanilkhanta, a program that recruited youth to assist the local government on myriad tasks ranging from environmental issues to higher education. The program, inspired by the observations of the ASER partnership process, 
was led by the staff member of the mayor's secretariat who initially advocated for ASER.

In addition, several of the ASER Budanilkantha quality monitors approached the mayors of their municipalities with proposals to conduct ASER.

An important observation and learning from the ASER Nepal partnership model was the missed opportunity to create sustained engagement of the local youth with local families, schools, and municipal stakeholders about the findings on children's learning levels and resulting recommendations to improve education. Many youth assessors were highly motivated to continue working on improving the learning of children when they observed the low learning levels. One assessor said to an ASER trainer, "I was shocked that the children who live in a house I pass every day on my way to college can't even recognize the letters of the alphabet. I thought everyone who went to school could do that. How is this possible? What can I do about it?" For the ASER team to keep the youth assessors engaged to respond to the findings at local government levels for an extended period of time was not a tenable solution. However, this sustained engagement would be necessary to foster accountability at the grassroots level, in addition to government ownership. Therefore, future implementations of the partnership model should develop a communications and engagement strategy from the outset. This could include, for example, another local partner or NGO with a focus on continued advocacy at both government and grassroots levels to leverage the young assessors' role and enable engagement beyond the assessment to improve education at all levels. Most recently this has been realized in the ASER Nepal implementation in Tulsipur Municipality of Lumbini Province (PAL Network, 2021). In Tulsipur, a local partner (a civil society group of local youths) from the same municipality designed and conducted the assessment, with support from the ASER Nepal team at GalliGalli (Tulsipur Submetropolitan City, 2021).

Altogether, the positive experiences of the municipal level ASER in Budanilkantha have led to the conclusion that the ASER Nepal partnership model is a successful strategy to tackle education issues at both the local government and grassroots levels. In the Nepali context, socially active youth and young people who study in the capital have credibility in their local neighborhoods, and hence can make a difference. At the same time, local governments are responsible for education policy, and have the power to initiate interventions to improve education. 


\section{ASER BANGLADESH: A TOOL FOR EDUCATION POLICY ADVOCACY}

\subsection{Background}

The Institute of Informatics and Development (IID) is a public policy institute, established in Bangladesh in 2012. The organization's vision is to "make policy public" for an informed, inclusive, and democratic society, which could be achieved by its $3 i$ mission:
i. inquire evidence for policy
ii. inform people and policy makers
iii. involve public in public policy.

While IID's initial focus spanned policy issues such as youth and gender, democracy and pluralism, and education and skills, there was a strongly felt need to build on policy research, assessment, and advocacy relating to education. IID as the secretariat of ASER Bangladesh first introduced CLAs in Bangladesh in 2014. There were several factors that foregrounded this development.

The rapid expansion of primary school access has been central to Bangladesh's education policy. It is one of the few countries in the world that ensured gender parity up to the secondary level by 2005 (Asian Development Bank, 2018). By 2019, the net enrollment rate had increased to $98 \%$ (Directorate of Primary Education, 2019). CSOs and NGOs have played a crucial role in primary education and assessment.

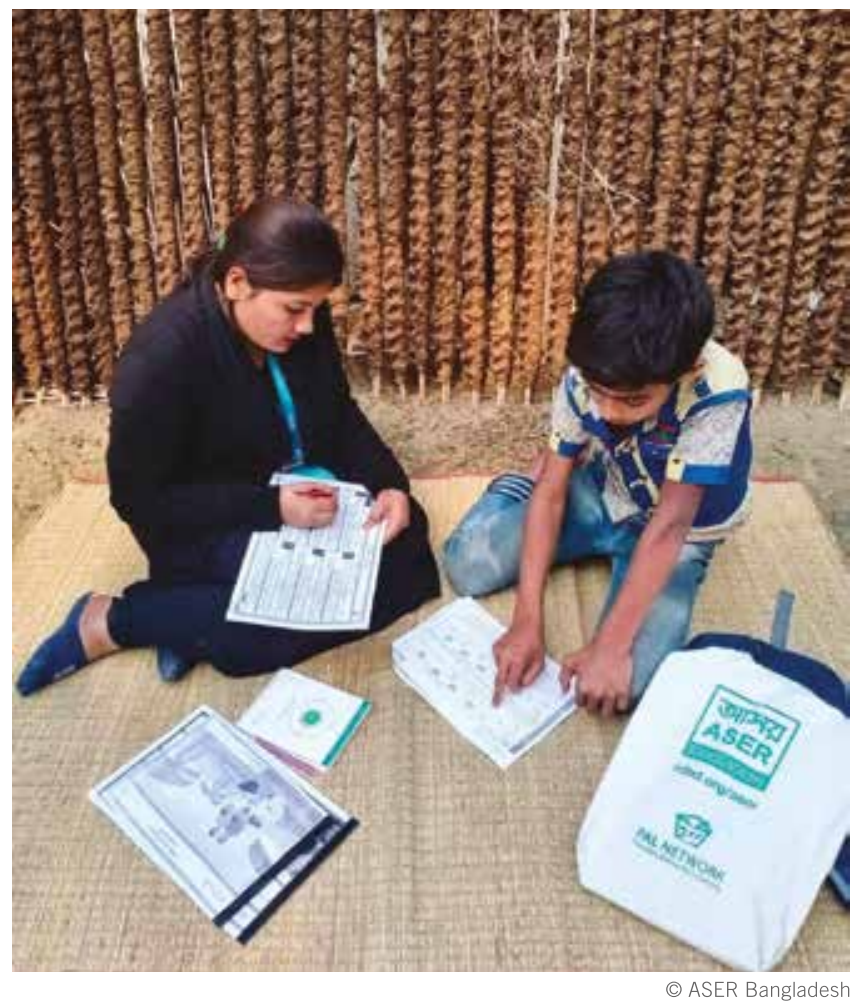

The Campaign for Popular Education started publishing the Education Watch Report from 1999, where the focus was on quantitative aspects of primary education such as access, attendance, dropout rates, and gender parity. The focus shifted towards quality and equity in the following reports. However, despite these developments, there has been little to no data to understand whether increasing access has resulted in raising foundational learning outcomes. Further, traditional education assessments, such as the annual summative assessments conducted by the government, assessed children in school and did not capture basic competencies.

As we enter the decade of action to fulfil education targets under SDG 4, Bangladesh still needs to put significant effort to attain many of these goals. Learning poverty still remains an issue (Directorate of Primary Education, 2017), where partnerships between government and non-government actors can play a vital role in bridging this social and economic learning gap. We aim to use ASER Bangladesh as a tool of policy advocacy, as it has been IID's major strength. ${ }^{14}$ Therefore, ASER Bangladesh plays a key role in maximizing impact on education policy and decision-making.

\subsection{Early stages of CLA implementation}

Education has been a core area of IID's policy advocacy since it was established in 2012. A focus of the early stages was policy research and analysis to provide evidence of the relationship between official policy and actual implementation. Important areas of focus included key aspects of the education system such as education financing, education administration, school infrastructure, school governance and management, access, participation, and enrollment. IID also undertook evaluations of different education programs. It was believed there was a need to strengthen the engagement of citizens with policy makers, in order to increase the impact of IID's policy research, and to enhance IID's advocacy role for quality education. As a result, IID in partnership with ActionAid Bangladesh conducted the Citizens' Report on Primary Education study (IID \& ActionAid Bangladesh, 2005). The study focused on examining the provision of quality education from an education rights-based perspective. Since most of the interviews and observations for the study were conducted in schools, outof-school children were not reached. This was considered a major gap in the study, especially because vulnerable children from disadvantaged communities and children with special needs often have limited access to schools. The second major gap in the study was the absence of primary data on learning outcomes to report on the right to quality learning. Indicators

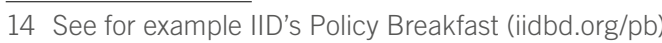


on active learning hours, parents' satisfaction with what is taught in schools, and the use of play were used instead (IID \& ActionAid Bangladesh, 2005).

The National Student Assessment program was initiated in 2006 (Directorate of Primary Education, 2017), and some CSOs conducted surveys at a small scale to assess achievement in primary education. Yet the timely availability and accessibility of data on representative learning outcomes on a large scale have remained a concern for IID's education policy research and advocacy role for many years.

The gap of accessible and useful learning outcomes data for education policy evaluation and advocacy was emphasized by an education campaign undertaken in a collaboration between IID and BRAC ${ }^{15}$ in 2014. As part of this campaign, IID representatives were invited to BRAC's second annual Frugal Innovation Forum conference where they learnt about the CLA approach. At the conference, ASER India presented the ASER methodology, which was seen as the perfect fit for IID's education policy research and advocacy role in order to fill the existing gaps and generate representative, large-scale data on children's foundational reading and mathematical skills, including of out-of-school children.

In 2014, IID conducted a small-scale pilot assessment in Gaibandha, Bangladesh. IID took up the ASER tool and contextualized it in alignment with the minimum proficiency levels for reading and mathematics in the National Curriculum of Bangladesh (National Curriculum and Textbook Board, 2017). The pilot results were shared with ASER India and further collaboration was initiated. Meanwhile, BRAC was highly interested in the pilot results and approached IID with a seed fund to conduct a second pilot in two districts of Sylhet division of Bangladesh with 791 children. The second pilot found "very low level of basic competencies at the primary level. For instance, only $24 \%$ students of class 3 ; only $47 \%$ students of class 4 and $63 \%$ student of class 5 were able to read basic English words during the survey" (Institute of Informatics and Development, 2015). ${ }^{16}$

Since the pilot survey also collected information on household indicators such as per capita household income (monthly), electricity connection at home, and whether children assisted their parents in income-generating activities, useful links were established connecting learning outcomes to multiple socioeconomic characteristics. To communicate the findings to the government and other CSOs, IID and BRAC jointly organized a policy advocacy event for high officials from the

15 BRAC is an international development organisation based in Bangladesh. For more information see http://www.brac.net/. 16 Basic competencies low among primary students - IID (iidbd.org) government of Bangladesh and CSO leaders. Those highlevel policy makers, including ministers, agreed that there was a need for a common monitoring platform to evaluate the development of the education sector.

Based on this success with the pilot implementation, CLA was considered a viable tool to fill the data gap on children's learning outcomes. Given the common interest, IID formed ASER Bangladesh in partnership with BRAC in 2014. Since then, ASER Bangladesh has built its capability on CLAs through training support from ASER Centre and conducting small-scale pilots. To date, ASER Bangladesh has implemented five pilot assessments to sharpen its capacity on implementing CLA in Bangladesh.

\subsection{ASER Bangladesh's role in policy advocacy}

Engaging with national-level policy makers within the centralized governance structure of Bangladesh's government is a crucial aspect of IID's work. One of the powerful tools to bring government together with citizens and CSOs has been IID's flagship initiative - the Policy Breakfast. ${ }^{17} \mathrm{~A}$ small group of influential representatives, including from within the government, get together for an informal discussion under the Chatham house rules. ${ }^{18}$ The objective is to promote evidenceinformed and solution-driven debates among key influencers of the policy community. This candid forum has been useful to facilitate engagement on issues relating to the economy, climate change, and education, among others.

IID's Policy Breakfast started gaining traction in 2015. Around the same time, CLA pilots were undertaken in Bangladesh, and the national assessment landscape in Bangladesh started to open up. This was influenced by the governments' Secondary Education Quality and Access Enhancement Project (SEQAEP), an impact assessment study of an educational intervention run by the government in 122 upazilas (subdistricts). From the first phase in 2011 to the third phase in 2015, the program was extended to include all secondary education institutions in Bangladesh, and the Learning Assessment for Secondary Institutions (LASI) was established, with the aim of providing regular, objective data on the quality of secondary education in

\footnotetext{
17 More information can be found at www.iidbd.org/pb

18 The rule originated at Chatham House with the aim of encouraging openness of discussion and facilitating the sharing of information. The Chatham House rule reads as follows: "When a meeting, or part thereof, is held under the Chatham House Rule, participants are free to use the information received, but neither the identity nor the affiliation of the speaker(s), nor that of any other participant, may be revealed." See https://www.chathamhouse.org/about-us/ chatham-house-rule.
} 
Bangladesh for system-level monitoring. ${ }^{19}$ With the introduction of LASI, the government also invested in capacity development of the Monitoring and Evaluation wing of the Ministry of Education, showing the government's commitment to evidencebased education policy (Killimangalam, 2019).

For IID, this welcome shift in government perception of using system-level data for evaluating learning outcomes and to shed light on gaps in the education system presented a prime opportunity to engage with high-level government stakeholders on the purpose and use of CLAs. At a seminar titled "Quality education for next generation" on 18 June 2015, representatives from BRAC, IID, and government discussed opportunities for coordinating government and private assessment efforts in order to develop an encompassing database for monitoring the quality of education. They "agreed that there is a need for a government-NGO joint platform to monitor the progress of the education sector of the country. They pledged to continue this collaboration to create a modern ICT enabled platform for such monitoring efforts" (Institute of Informatics and Development, 18 June 2015). Thus the seminar resulted in the agreement by BRAC, IID, and education ministries to jointly develop a "common online monitoring platform".

Along with the successful Policy Breakfast, IID has pioneered other advocacy initiatives such as Hello MP, Youth Manifesto and Policy Conclave. Each of these helps build an environment where citizens and politicians can regularly engage in the process of "making policy public" and come closer to decisionmaking processes.

\subsection{Conclusion}

ASER Bangladesh has proven to be an essential tool for citizens, CSOs, and policy makers alike to strongly advocate for quality education. By providing representative data on foundational reading and mathematics skills of children and young adults, including vulnerable and out-of-school populations, ASER Bangladesh closes an important data gap to inform education policy. This is of particular importance against the background of the impacts of the COVID-19 pandemic on all areas of life, including education. Having reliable tools and assessment systems in place is essential for governments to monitor learning progress, and to interpret change over time. Hence, implementing scalable and cost-effective assessments could be a major step towards regularly monitoring learning outcomes and foundational learning levels, which can inform policies for improving and ensuring quality learning.
With the government increasingly receptive to objective and external evaluation, particularly to conducting and using CLA data for monitoring purposes, ASER Bangladesh has the potential to contribute to Bangladesh's education monitoring system. Looking forward, CLAs will be a powerful tool in the post-COVID world to understand how foundational learning skills have been affected in this period of school closures and education interruption. ASER Bangladesh aims to fulfil this objective through future nationwide CLAs by leveraging IID's long partnership with key stakeholders including BRAC, PAL Network, and the government. 


\section{CONCLUSION}

This topical case study on CLAs began with a reference to the global problem of children being in school but not learning, even before the COVID-19 pandemic struck. As we write these case studies, the world has gone through a whole year of living with the pandemic. Schools in Bangladesh, India, Nepal, and Pakistan have been closed for a full academic year, with enormous uncertainty about when they will reopen and in what form.

The literature on learning loss suggests that the learning crisis will become much worse in the future. Two recent analyses based in South Asia are relevant here. Andrabi et al. (2020) analyzed the consequences for children four years after the 2005 earthquake in Pakistan. The researchers found that children living close to the fault line, especially children whose parents had low levels of education, scored significantly worse on academic tests than those who lived further away. Banerji (2020) examined data on learning loss over summer vacations. The study assessed foundational reading and numeracy skills of 1.5 million children in 22 districts of India's most populous state, Uttar Pradesh, at the beginning of the summer holidays (April 2019) and again in August 2019, after they had ended. The comparison between the two time points for children in Grades 3 and 4 showed a significant decline in foundational reading and numeracy skills over the summer holidays.

To mitigate the risks of an exacerbated learning crisis on a global scale, immediate action is required. The four ASER studies presented here have illustrated some of the ways in which the CLA model can be used to improve learning: from improving teaching practices in classrooms (India), to engaging community members in villages in finding solutions to improve learning (Pakistan), to supporting local governments in using evidence for educational planning (Nepal), to influencing policy makers through advocacy to address important education issues (Bangladesh). In each country, the CLA tool, process, and aggregate data are used in many more ways and for many more purposes than those reported in this topical case study. Globally, ASER has influenced the 2030 education development agenda around monitoring and reporting SDG 4 in education at various forums. The UNESCO Institute for Statistics (UIS), which has been mandated to monitor the progress of countries against SDG 4, acknowledges CLAs as an important data source for countries to report against the global minimum proficiency levels in reading and mathematics. ASER results are also regularly quoted in the UNESCO Global Monitoring Report (UNESCO, 2013-19).
The various ways in which the CLA model is used to improve learning has demonstrated the importance of communicating the problem of poor foundational skills to as many stakeholders as possible, both inside and outside the education system. Whether teachers, parents, community members, local government officials, national policy makers, or international organizations, a clear understanding of what the problem is, where it is, and how to solve it are the keys to providing children with the support they need for learning. 


\section{REFERENCES}

Andrabi, T., Daniels, B., Das, J. (2020). Human capital accumulation and Disasters: Evidence from the Pakistan earthquake of 2005. RISE Working Paper Series. 20/039. https://doi.org/10.35489/BSG-RISE-WP_2020/039

ASER Centre. (2017). Karnataka: School enrollment and reading. In Annual Status of Education Report (Rural) 2016. http://img.asercentre.org/docs/Publications/ ASER\%20Reports/ASER\%202016/State\%20pages\%20 English/karnataka_state_english.pdf

ASER Nepal. (2018). Annual Status of Education Report (ASER) Budanilkantha 2074: From evidence to action. ASER Centre. https://drive.google.com/file/d/12_vslr5Yq_ kOy4PDCleW2Ug1vAOHkZGZ/view

Asian Development Bank. (2018). Proposed results-based Ioan People's Republic of Bangladesh: Supporting Fourth Primary Education Development Program. https://www.adb.org/sites/default/files/projectdocuments/50192/50192-002-rrp-en.pdf

Banerji, R. (2017). Teaching "toppers" or learning for all? Annual Status of Education Report (Rural) 2016, (pp. 12-15). ASER Centre.

Banerji, R. (2017). When schooling doesn't mean learning. Stanford Social Innovation Review. https://ssir.org/articles/ entry/when_schooling_doesnt_mean_learning

Banerji, R. (2020). Learning "loss" and learning "gain" in primary school years: What do we know from India that can help us think forward in the COVID-19 crisis? RISE Insight Series. 2020/019. https://doi.org/10.35489/BSGRISE-RI_2020/019

Coffey International Development Limited. (2015). Baseline Report - Innovation Window. Evaluation Manager Girls' Education Challenge (GEC) Fund. https://assets. publishing.service.gov.uk/government/uploads/system/ uploads/attachment_data/file/646543/Baseline-reportInn-window-GEC.pdf

Coffey International Development Limited. (2017). Endline Evaluation Report - Innovation Window. Evaluation Manager Girls' Education Challenge (GEC) Fund. https:// assets.publishing.service.gov.uk/government/uploads/ system/uploads/attachment_data/file/700823/GirlsEducation-Challenge-Fund-Innovation-Window-EndlineReport.pdf
Directorate of Primary Education. (2017). The National Student Assessment 2017 Grades 3 and 5. Monitoring and Evaluation Division Directorate of Primary Education. http://dpe.portal.gov.bd/sites/default/files/files/dpe.portal. gov.bd/publications/24ec04b1_3064_41d3_9ac7_9b7 78a02e17b/The\%20National\%20Student\%20 Assessment\%20\%202017\%20Book\%20(1).pdf

Directorate of Primary Education. (2019). Bangladesh Primary Education Annual Sector Performance Report 2019. https://www.dpe.gov.bd/sites/default/ files/files/dpe.portal.gov.bd/publications/07c9f4cb_ c14a_49da_9201_7774c2aeef84/Final\%20ASPR\%20 2019.pdf

Hall, S. (2013). Increasing the access and quality of basic education for marginalized girls in Faryab: An educational baseline survey for ACTED. ACTED. https://static1. squarespace.com/static/5cfe2c8927234e0001688343/t/ 5e99751497b5844904265874/1587115311502/ACTEDGEC-Baseline.pdf

Institute of Informatics and Development \& ActionAid Bangladesh. (2005). Citizen's report on primary education from a rights-based perspective. http://iidbd.org/wpcontent/uploads/2015/01/iid-research-report-2.pdf

Institute of Informatics and Development. (June 2015). Children's basic learning competencies. http://iid.org. bd/wp-content/uploads/2015/09/iid-brief-report-basic_ learing.pdf

Institute of Informatics and Development (18 June 2015). Common monitoring platform for education to be developed. IID. www.iidbd.org/nb5421/

Killimangalam, A. (2019). Building standardised assessment capacity in Bangladesh. ACER. https://www.acer.org/ au/discover/article/building-standardised-assessmentcapacity-in-bangladesh

Ministry of Finance, Pakistan (2012-13). Economic Survey of Pakistan, chapter 10. Islamabad: Ministry of Finance. http://www.finance.gov.pk/survey/chapters_13/10Education.pdf

Nag, S. (2017). Assessment of literacy and foundational learning in developing countries. Health and Education Advice and Resource Team. https://www.heart-resources. org/wp-content/uploads/2017/06/Assessment-of-literacyand-foundational-learning-in-developing-countries.pdf

National Curriculum and Textbook Board. (2017). Curriculum for primary: Bangla. http://www.nctb.gov.bd/sites/default/ files/files/nctb.portal.gov.bd/files/3bfe97e7_f8b0_4661_ baa9_7dbc464cd014/1.\%20Bangla.pdf 
National Curriculum and Textbook Board. (2017). Curriculum for primary: English. http://www.nctb.gov.bd/sites/default/ files/files/nctb.portal.gov.bd/files/3bfe97e7_f8b0_4661_ baa9_7dbc464cd014/3.\%20EnglishCurri.pdf

National Curriculum and Textbook Board. (2017). Curriculum for primary: Math. http://www.nctb.gov.bd/sites/default/ files/files/nctb.portal.gov.bd/files/3bfe97e7_f8b0_4661_ baa9_7dbc464cd014/2.\%20Math_Primary.pdf

National Institute for Educational Planning and Administration. (2018). U-DISE Flash Statistics: 2016-17.

PAL Network (2018). ASER Afghanistan joins the citizen led assessment folds. https://palnetwork.org/aser-afghanistanjoins-the-citizen-led-assessment-folds/

PAL Network. (2021). PAL Network Newsletter March 2021, 15(20). https://mailchi.mp/c634b4fb4b4e/pal-networknewsletter-quarter-1-2021

Save the Children. (2015). Children of Uruzgan Final Evaluation. https://www.savethechildren.org.au/getmedia/8f4aeld1c8a9-4501-bc7f-a745aa8056c0/AFG_Children-ofUruzgan_Evlaution_2015.pdf.aspx

Tulsipur Sub-Metropolitan City. (2021). ASER Report Tulsipur. https://tulsipurmun.gov.np/en/content/aser-report-tulsipur.

UNESCO (2013). The global learning crisis. Why every child deserves a quality education. https://unesdoc.unesco.org/ ark:/48223/pf0000223826

UNESCO (2015). Education for all 2000-2015: Achievements and challenges.

UNESCO (2016). The effects of police literacy training in Afghanistan: Case Study No. 4. Internal Oversight Service, Evaluation Office. IOS/EVS/PI/156.REV. https://docplayer. net/56818290-The-effects-of-police-literacy-training-inafghanistan-case-study-evaluation-of-unesco-s-role-ineducation-in-emergencies-and-protracted-crises.html

UNESCO Institute for Statistics (2016). Understanding what works in oral reading assessments: Recommendations from donors, implementers and practitioners.

Vagh, S.B. (2016). Is simple, quick and cost-effective also valid? Evaluating the ASER Hindi reading assessment in India. In UNESCO Institute for Statistics, Understanding what works in oral reading assessments (pp. 202-212). UNESCO Institute for Statistics. http://uis.unesco.org/sites/ default/files/documents/understanding-what-works-inoral-reading-assessments-2016-en.pdf

World Bank. (2019). Ending learning poverty: What will it take? https://openknowledge.worldbank.org/ handle/10986/32553. 


\section{APPENDIX: ADDITIONAL RESOURCES ABOUT CITIZEN-LED ASSESSMENTS}

\subsection{About ASER}

ASER Centre (2015). The why, what and how of ASER. Annual Status of Education Report (Rural) 2014.

ASER Centre (n.d.) Frequently asked questions about ASER. http://img.asercentre.org/docs/Publications/ ASER\%20Reports/ASER\%202016/Report\%20sections/ frequentlyaskedquestionsaboutaser_english.pdf

Banerji, R. (2016). Annual Status of Education Report (ASER) Assessment in India: Fast, rigorous and frugal. In UNESCO Institute for Statistics, Understanding what works in oral reading assessments (pp. 187-200). Montreal: UIS.

Banerji R, Bhattacharjea S, \& Wadhwa W. (2013). The Annual Status of Education Report (ASER). Research in Comparative and International Education 8(3): 387-396. https://doi.org/10.2304/rcie.2013.8.3.387

\subsection{About the PAL Network}

PAL Network. (2019). Fact Sheet. PAL Network. https:// palnetwork.org/wp-content/uploads/2019/11/2019_PALFactsheet_Finalized_September.pdf

\subsection{About the International Common Assessment of Numeracy (ICAN)}

International Common Assessment of Numeracy, https:// palnetwork.org/ican

PAL Network. (2020). ICAN: International Common Assessment of Numeracy. Background, Features and Large-scale Implementation. Nairobi: People's Action for Learning Network. https://palnetwork.org/wp-content/ uploads/2020/07/2020_PAL-Network_ICAN-Report_ EN.pdf

PAL Network (2020). ICAN: International Common Assessment of Numeracy. Sample Design. Nairobi: People's Action for Learning Network. https://palnetwork.org/wp-content/ uploads/2020/12/EN_ICAN_SamplingNote.pdf

PAL Network (2020). ICAN: International Common Assessment of Numeracy. Tool brochure: English. Nairobi: People's Action for Learning Network. https://palnetwork.org/wpcontent/uploads/2020/06/2020_ICAN-Tool_Brochure_ EN.pdf

\subsection{About Teaching at the Right Level (TaRL)}

Banerjee, A., Banerji, R., Berry, J., Duflo, E., Kannan, H., Mukherji, S., Shotland, M., \& Walton, M. (2016). Mainstreaming an effective intervention: Evidence from randomized evaluations of "Teaching at the Right Level" in India. NBER Working Paper No. 22746. https://www.nber. org/papers/w22746

Banerjee, A., Banerji, R., Berry, J., Duflo, E., Kannan, H., Mukherji, S., Shotland, M., \& Walton, M. (2017). From proof of concept to scalable policies: challenges and solutions, with an application. Journal of Economic Perspectives 31(4): 73-102. https://doi.org/10.1257/ jep.31.4.73

Banerji, R. (2015). 'Teaching at the right level': Solutions for low learning levels in India. PAL Network. https://palnetwork. org/teaching-at-the-right-level-solutions-for-low-learninglevels-in-india/

Pratham Education Foundation. Teaching at the right level. New Delhi: Pratham Education Foundation. https://www. pratham.org/about/teaching-at-the-right-level/

Poverty Action Lab. Teaching at the right level to improve learning. Poverty Action Lab. https://www. povertyactionlab.org/case-study/teaching-right-levelimprove-learning

UNESCO. (2020). Teaching at the right level: From concern with exclusion to challenges of implementation. Paper commissioned for the 2020 Global Education Monitoring Report, Inclusion and education. https://unesdoc.unesco. org/ark:/48223/pf0000373668?locale=en 
Using Assessment Data in Education Policy and Practice: Examples from the Asia-Pacific

\section{Series editors}

Mark Manns, UNESCO Bangkok

Ursula Schwantner, Australian Council for Educational Research

Citizen-led assessments: A model for evidence-based advocacy and action to improve learning

Australian Council for Educational Research Limited (c) 2021

The Australian Council for Educational Research

19 Prospect Hill Road

Camberwell VIC 3124

Phone: (03) 92775555

ABN 19004398145

www.acer.org

www.acer.org/gem

https://bangkok.unesco.org/theme/neqmap

ISBN 9781742866369

\section{(c) $(1) \Theta \Theta$}

With the exception of any material protected by a trademark, and where otherwise noted, all material presented in this document is provided under a

Creative Commons Attribution NonCommercial NoDerivatives 4.0 International Licence

\section{Recommended attribution}

The Australian Council for Educational Research must be attributed as the copyright holder of this publication. To request use outside this licence, email permissions@acer.org

\section{Recommended citation}

Bhattacharjea, S., Saeed, S., Timalsina, R., \& Ahamed, S. (2021). Citizen-led assessments: A model for evidence-based advocacy and action to improve learning. https://doi.org/10.37517/978-1-74286-636-9

\section{Acknowledgements}

This topical case study is the fourth in the Using Assessment Data in Education Policy and Practice: Examples from the Asia-Pacific series initiated by the Network on Education Quality Monitoring in the Asia-Pacific (NEQMAP) at UNESCO Bangkok and the Global Education Monitoring Centre (GEM Centre).

This publication has been funded by the Australian Government through the Department of Foreign Affairs and Trade, and the Australian Council for Educational Research Ltd. The views expressed in this publication are the author's alone and are not necessarily the views of the Australian Government. 
